OPEN ACCESS

Edited by:

Ramin Massoumi,

Lund University, Sweden

Reviewed by:

Thomas Brzozowski,

Jagiellonian University Medical

College, Poland

Jianwei Zhou,

Nanjing Medical University, China

*Correspondence:

Hanne-Line Rabben

hanne.l.rabben@ntnu.no

Specialty section: This article was submitted to

Gastrointestinal and

Hepatic Pharmacology,

a section of the journal

Frontiers in Pharmacology

Received: 02 October 2020

Accepted: 09 February 2021

Published: 08 April 2021

Citation:

Rabben H-L, Kodama Y, Nakamura M,

Bones AM, Wang TC, Chen D,

Zhao C-M and Øverby A (2021)

Chemopreventive Effects of Dietary

Isothiocyanates in Animal Models of

Gastric Cancer and Synergistic

Anticancer Effects With Cisplatin in

Human Gastric Cancer Cells.

Front. Pharmacol. 12:613458.

doi: 10.3389/fphar.2021.613458

\section{Chemopreventive Effects of Dietary Isothiocyanates in Animal Models of Gastric Cancer and Synergistic Anticancer Effects With Cisplatin in Human Gastric Cancer Cells}

\author{
Hanne-Line Rabben ${ }^{1,2 *}$, Yosuke Kodama ${ }^{1}$, Masahiko Nakamura ${ }^{3}$, Atle Magnar Bones ${ }^{4}$, \\ Timothy Cragin Wang ${ }^{1,5}$, Duan Chen ${ }^{1}$, Chun-Mei Zhao ${ }^{1,2}$ and Anders Øverby ${ }^{1,3}$ \\ ${ }^{1}$ Department of Clinical and Molecular Medicine, Norwegian University of Science and Technology (NTNU), Trondheim, Norway, \\ ${ }^{2}$ The Central Norway Regional Health Authority, Stjørdal, Norway, ${ }^{3}$ Center for Clinical Pharmacy and Clinical Sciences, School of \\ Pharmacy, Kitasato University, Tokyo, Japan, ${ }^{4}$ Cell, Molecular Biology and Genomics Group, Department of Biology, Norwegian \\ University of Science and Technology (NTNU), Trondheim, Norway, ${ }^{5}$ Division of Digestive and Liver Diseases, Columbia University \\ College of Physicians and Surgeons, New York, NY, United States
}

Naturally occurring isothiocyanates (ITCs) from edible vegetables have shown potential as chemopreventive agents against several types of cancer. The aims of the present study were to study the potential of ITCs in chemoprevention and in potentiating the efficacy of cytotoxic drugs in gastric cancer treatment. The chemoprevention was studied in chemically induced mouse model of gastric cancer, namely $\mathrm{N}$-methyl- $\mathrm{N}$-nitrosourea (MNU) in drinking water, and in a genetically engineered mouse model of gastric cancer (the so-called INS-GAS mice). The pharmacological effects of ITCs with or without cisplatin were studied in human gastric cell lines MKN45, AGS, MKN74 and KATO-III, which were derived from either intestinal or diffused types of gastric carcinoma. The results showed that dietary phenethyl isothiocyanate (PEITC) reduced the tumor size when PEITC was given simultaneously with MNU, but neither when administrated after MNU nor in INS-GAS mice. Treatments of gastric cancer cells with ITCs resulted in a timeand concentration-dependent inhibition on cell proliferation. Pretreatment of gastric cancer cells with ITCs enhanced the inhibitory effects of cisplatin (but not 5-fluorouracil) in timeand concentration-dependent manners. Treatments of gastric cancer cells with PEITC plus cisplatin simultaneously at different concentrations of either PEITC or cisplatin exhibited neither additive nor synergetic inhibitory effect. Furthermore, PEITC depleted glutathione and induced $\mathrm{G}_{2} / \mathrm{M}$ cell cycle arrest in gastric cancer cells. In conclusion, the results of the present study showed that PEITC displayed anti-cancer effects, particularly when given before the tumor initiation, suggesting a chemopreventive effect in gastric cancer, and that pretreatment of PEITC potentiated the anti-cancer effects of cisplatin, possibly by reducing the intracellular pool of glutathione, suggesting a possible combination strategy of chemotherapy with pretreatment with PEITC.

Keywords: dietary (or plant) isothiocyanates, gastric cancer, glutathione, glutamine, cisplatin, mice 


\section{INTRODUCTION}

Gastric cancer is one of the leading causes of cancer in the world with over one million new cases reported in 2018 (GLOBOCAN) (Ferlay et al., 2013; Bray et al., 2018). Despite dramatic decline in gastric cancer incidences in later years, gastric cancer is the fifth most common cancer with a 5-year survival rate below $25 \%$, making gastric cancer the third leading cause of cancer mortality worldwide (Ferlay et al., 2010; Ferlay et al., 2013). Chemoprevention of gastric cancer is to chemically prevent or delay the occurrence of malignancy. Although Helicobacter pylori (H. pylori) eradication can be an effective preventive method due to the putative pathogenic mechanisms, the chemoprevention using natural, synthetic or biological agents has enormous potential, given the high incidence together with the healthcare costs of treatment (Steward and Brown, 2013; Tan and Wong, 2013; Dunn et al., 2016). The treatments of gastric cancer include surgery, and chemotherapy regimens with either mono-chemotherapy (using single drug) or combination-chemotherapy (e.g., fluoropyrimidines and platinum-based therapies) for inoperable or metastatic gastric cancer (Van Cutsem et al., 2006; Cunningham et al., 2008; Koizumi et al., 2008; Kang et al., 2009; Orditura et al., 2014). However, patients with unresectable advanced gastric cancer usually have poor outcomes with median survivals of 10-18 months. Nearly half of patients with resectable gastric cancer have a recurrence and median survival is about 6 months (Leiting and Grotz, 2019). Thus, a challenge for improving patient care of gastric cancer in terms of survival and quality of life appears to be ineffective cytotoxic chemotherapy. These facts indicate that there are still great needs for improvement in the prevention and treatment of gastric cancer. Previously, we have showed that denervation (surgically, pharmacologically or genetically) suppressed the tumorigenesis of gastric cancer, which was associated with a decrease in $\mathrm{WNT} / \beta$-catenin signaling, the suppression of stem cell expansion through M3 receptor-mediated cholinergic signaling and the reversion of metabolic reprogramming, and that the combination of denervation and mono-chemotherapy led to an enhanced effect on tumor growth and survival in an animal model of gastric cancer (Zhao et al., 2014; Rabben et al., 2016). Recently, we have further shown that neural signaling modulated metabolism of gastric cancer, reflected by metabolic switch from glutaminolysis to OXPHOS/glycolysis and normalization of the energy metabolism after denervation (Rabben et al., 2021). In the present study, we wanted to explore the potential of a class of anti-cancer agents, isothiocyanates (ITCs) for chemoprevention and enhancement of chemotherapy as they are also shown to interfere with tumor metabolism (Conaway et al., 2002; Lv et al., 2020).

Naturally occurring isothiocyanates (ITCs) are electrophilic plant phytochemicals derived from glucosinolates of edible vegetables such as broccoli, cauliflower, brussels sprouts, and cabbage. Phenethyl isothiocyanate (PEITC) has been tested in in vitro, in vivo and in clinical trials to study about the potential effects of prevention and treatment of different types of cancer (Hu and Morris, 2004; Keum et al., 2004; Keum et al., 2005; Clarke et al., 2008; Chu et al., 2009; Wu et al., 2009; Li et al., 2010; Tomczyk and Olejnik, 2010; Zhang, 2010; Chung et al., 2013; Li and Zhang, 2013). The aims of the present study were to study whether ITCs could prevent gastric tumorigenesis and whether ITCs could enhance the inhibitory effect of mono-chemotherapy on gastric cancer; and if so, to investigate the possible underlying mechanisms. To these ends, we utilized chemically induced mouse model of gastric cancer, i.e., N-methyl-N-nitrosourea (MNU) in drinking water, and genetically engineered mouse model of gastric cancer (the socalled INS-GAS mice) for studying chemoprevention, and used human gastric cancer cell lines, i.e., MKN45, AGS, MKN74 and KATO-III derived from either intestinal or diffused types of gastric carcinoma for studying the pharmacological effects of ITCs with or without cisplatin in vitro.

The possible mechanisms underlying the anti-cancer effects of ITCs have been suggested to involve inhibition of cytochrome P450 enzymes, induction of phase II detoxification enzymes, such as glutathione S-transferase (GST) and apoptosis, and cell cycle arrest, inhibition of migration, disruption of microtubules, and dysregulation of signaling pathways including major regulators such as $\mathrm{WNT} / \beta$-catenin signaling pathway, NRF2, ERK, Jun and Akt signaling pathways (Yang et al., 2010; Gupta et al., 2014; Øverby et al., 2014; Lawson et al., 2015; Chen et al., 2018). In addition, glutathione (GSH) is a powerful regulatory tripeptide with antioxidant function that protects cells from oxidative stress by removing free radicals and peroxides. We and others have shown that ITCs conjugate with GSH, leading to depletion of GSH, elevation of oxidative stress and expression of GST-encoding genes, and that there are close relationship between glutathione and the levels of glutamine and glutamate in the cell-pool important for redox homeostasis (Øverby et al., 2015). Thus, we hypothesized that ITCs would enhance the cytotoxicity of cisplatin by depleting cells of GSH, and thus measured the levels of GSH and the ratio between glutamine and glutamate in connection with cell growth inhibition after treatment of ITCs.

\section{MATERIALS AND METHODS}

\section{Animals and Experimental Groups}

All mice at ages between 1-12 months were housed three to four mice per cage on wood chip bedding with a $12 \mathrm{~h}$ light/dark cycle, room temperature of $22^{\circ} \mathrm{C}$ and $40-60 \%$ relative humidity at the standard housing conditions in a specific pathogen-free environment. Ninety mice including 54 wild-type (FVB) mice and 26 INS-GAS mice were divided into the following experimental groups: FVB mice $(n=16$, eight male, eight female), FVB mice + MNU ( $n=11$, five female, six male), FVB mice $+\mathrm{MNU}+$ prePEITC $(n=16$, eight female, eight male), FVB mice + MNU + postPEITC ( $n=11$, five female, six male), INS-GAS mice ( $n=24,10$ female, 14 male), and INS-GAS mice + PEITC ( $n=12$, six female, six male). In each experiment, mice were randomly divided into different subgroups with gender-balance. 


\section{Treatment of Phenethyl Isothiocyanate in a Chemically Induced Mouse Model of Gastric Cancer}

The chemically induced gastric cancer model (FVB + MNU) was established according to our previous report (Zhao et al., 2014). In brief, mice were exposed to N-Methyl-N-nitrosourea (MNU, Sigma Chemicals), which was dissolved in distilled water at a concentration of $240 \mathrm{ppm}$ and freshly prepared twice per week for administration in drinking water in light-shielded bottles ad libitum. MNU was administered in the drinking water starting at 4 weeks of age and continued from the next 10 weeks followed by euthanization at age 12 months. PEITC was administered through an AIN-76A diet (3-5 $\mu \mathrm{mol}$ PEITC/g diet) either during or following administration of MNU. Mice were euthanized at age of 12 months.

\section{Treatment of Phenethyl Isothiocyanate in Genetically Engineered Mouse Model of Gastric Cancer}

The transgenic insulin-gastrin mice (INS-GAS mice) that overexpress gastrin develop spontaneously gastric cancer were generated as previously described (Zhao et al., 2014). Mice received PEITC through an AIN-76A diet (3-5 $\mu$ mol PEITC/g diet) for 10 weeks or standard pellet food (RM1801002, Scanbur BK AS). Mice were euthanized at the age of 12 months.

\section{Tissue Sampling}

The stomachs were removed, opened along the greater curvature, washed in $0.9 \%(\mathrm{w} / \mathrm{v}) \mathrm{NaCl}$, and pinned flat on a petri-dish-silicone board. Each stomach was photographed digitally; the tumor profiles in both anterior and posterior sides of the stomach were drawn separately and subjected to morphometric analysis of the volume density (expressed as the percentage of glandular volume occupied by the tumor) using point-counting technique with a test grid comprised of a $1.0 \mathrm{~cm}$ square lattice. This grid was placed over each photograph $\left(40 \mathrm{~cm}^{2} \times 30 \mathrm{~cm}^{2}\right)$, and the numbers of test points overlying the tumor and gastric glandular area were determined.

\section{Chemicals and Reagents}

Phenethyl isothiocyanate (PEITC, Sigma Aldrich, United States, cat. no. 253731-5G), Benzyl isothiocyanate (BITC, Sigma Aldrich, Poland, cat. no. 252492-5G) and Allyl isothiocyanate (AITC, Sigma Aldrich, Germany, cat. no. 377430-100G) were dissolved in 100\% dimethylsulfoxide (DMSO) to working concentrations. Cisplatin (Wako Pure Chemical Industries Ltd., Osaka, Japan, cat. no. 03320091, Lot. SAQ1693 or TOCRIS Bioscience, Abingdon, United Kingdom, cat. no. 2251) was dissolved in PBS (Nacalai Tescue, Japan, cat. no. 14249-24) under gentle warming, and 5fluorouracil (Sigma Aldrich, China) was dissolved in 100\% DMSO. The following cell culture supplements were used: DMEM (Nacalai tesque, Japan, cat. no 08456-65); Fetal Bovine Serum (FBS; ThermoFisher Scientific, United States), antibiotic-antimycotic solution containing penicillin, streptomycin and amphotericin B (Nacalai tesque, Japan, cat. no. 02892-54), Penicillin-streptomycin solution (Sigma Aldrich, Oslo, Norway, cat. no. P4333-100ML),
RPMI-1640 medium (Sigma Aldrich, Norway, cat. no. R8758$500 \mathrm{ML}$ with $0.3 \mathrm{~g} / \mathrm{L}(2 \mathrm{mM})$ glutamine), DMEM (Gibco, ThermoFisher Scientific, Oslo, Norway, cat. no. A14430-01 without L-glutamine, D-glucose, phenol red and sodium pyruvate); dialyzed FBS (Life technologies, United States, Cat. no 26400-036); L-glutamine (Sigma Aldrich, Oslo, Norway, cat. no G7513); Sodium pyruvate (Sigma Aldrich, Oslo, Norway, cat. no. S8636). For cell cycle analysis: Propidium iodide (P1, Sigma Aldrich, Oslo, Norway, cat. no P4170-10MG); Triton-X (Sigma Aldrich, Oslo, Norway, cat. no. T9284), RNase A (Sigma Aldrich, Oslo, Norway, cat. no R4875-100MG). For GSH determination: 5Sulfosalicylic acid (SSA) solution (5.0\%); For Western Blot: RIPA cell lysis buffer (Pierce) containing 0.1\% MG132 Proteasome Inhibitor (Cayman Chemical), 1.0\% Protease inhibitor cocktail (Sigma Aldrich) and 10\% PhosStop Phosphatase Inhibitor Cocktail (Roche). Antibodies: Primary antibody mouse monoclonal anti human p53 clone DO-1 (Santa Cruz: sc-126); Mouse monoclonal anti- $\beta$-actin clone; Anti-mouse IgG HRP-linked whole Ab sheep (GE Healthcare: NA931)/Anti-Rabbit IgG, HRP-linked whole Ab donkey (GE Healthcare: NA934).

\section{Cell Culture}

Human gastric carcinoma cancer cell lines AGS and MKN45 were maintained in Dulbecco's Modified Eagle's Medium (DMEM; Nacalai tesque, Japan) supplemented with $10 \%$ fetal bovine serum and $1 \%$ antibiotic-antimycotic solution containing penicillin, streptomycin and amphotericin $\mathrm{B}$ in a humidified incubator holding $5 \% \mathrm{CO}_{2}$ and $37^{\circ} \mathrm{C}$. Human gastric carcinoma cancer cell lines MKN74 and KATO-III were maintained in RPMI-1640 medium supplemented with $10 \%$ FBS and $1 \%$ penicillinstreptomycin solution. Passages were performed when cultures reached $70-80 \%$ confluency. For the studies investigating glutamate and glutamine contents, DMEM containing $4.5 \mathrm{~g} / \mathrm{L}$ glucose, $2 \mathrm{mM}$ glutamine or $0.2 \mathrm{mM}$ glutamine and $1 \mathrm{mM}$ sodium pyruvate supplemented with dialyzed FBS was used.

\section{Proliferation Assay}

For proliferation assay, 1,500 cells of AGS, 2,500 of MKN45 or MKN74 or 3,000 cells of KATO-III were seeded in 96-well plates before incubated overnight allowing cells to confluate. Treatments were always accompanied by vehicle controls $(n=$ $12)$ on each plate $(0.05 \%$ DMSO). Cells were treated with AITC (Sigma Aldrich, Germany), BITC (Sigma Aldrich, Poland), PEITC (Sigma Aldrich, United States), cisplatin (Wako Pure Chemical Industries Ltd., Japan) or (Tocris, Norway) and 5fluorouracil (Sigma Aldrich, China) as indicated in the text. Following treatment, Cell Count Reagent SF (Nacalai tesque, Japan) was added according to providers' instructions to each well before mixing and incubating for 1.0-1.5 h. Proliferation was determined by measuring absorbance at $450 \mathrm{~nm}$ using a well plate reader. Defined DMEM was used to perform experiments with controlled levels of glutamine and glucose.

\section{Cell Cycle Analysis}

Human gastric cancer cells KATO-III were seeded as $2.5 \times 10^{5}$ cells in 6-well plates and incubated over two nights before treated with 0,5 or $10 \mu \mathrm{M}$ PEITC for 12 and $24 \mathrm{~h}$ or PEITC $(0,5,10 \mu \mathrm{M})$ 
together with cisplatin $(25$ or $50 \mu \mathrm{M})$ for $24 \mathrm{~h}$. Cells were harvested, resuspended in PBS and fixated in chilled ethanol $\left(-20^{\circ} \mathrm{C}, 70 \%\right.$, Kemetyl Norway) for minimum $15 \mathrm{~min}$. Cells were then pelleted and resuspended in freshly prepared propidium iodide (PI) staining solution $(0.25 \%$ Triton- X-100, $50 \mu \mathrm{g} / \mathrm{ml}$ PI and $200 \mu \mathrm{g} / \mathrm{ml}$ RNase A) for $30 \mathrm{~min}$. Cell cycle distribution was analyzed using a FACS Canto flow cytometer counting $2 \times 10^{4}$ cells per sample in triplicates. Cell cycle distribution was acquired from the obtained histograms using FACS Diva software.

\section{Morphology}

To study the effect of PEITC on cells, AGS and MKN74 cells were seeded in $\mathrm{T}_{25}$ flasks $\left(1.5 \times 10^{5}\right.$ cells per flask) and left for overnight incubation before treating with $5-20 \mu \mathrm{M}$ PEITC or vehicle control $(0.1 \%$ DMSO) for $24 \mathrm{~h}$. The cultures were then observed and pictures captured through an inverted microscope in phase contrast mode.

\section{Total GSH Determination}

Total cellular glutathione level was determined in PEITC, AITC or BSO-treated AGS cells. Cells were seeded in $\mathrm{T}_{25}$ flasks $(1.5 \times$ $10^{5}$ cells per flask) and incubated overnight prior to treatment. The cultures were treated with either $10-20 \mu \mathrm{M}$ PEITC, $50-100 \mu \mathrm{M}$ AITC, or $0-100 \mu \mathrm{M}$ BSO or vehicle control $(0.1 \%$ DMSO) for 3 or $6 \mathrm{~h}$. The doses were based on $\mathrm{IC}_{50}$-range and previous literature. Each treatment was performed in quadruples. Cells were harvested and centrifuged (1,500 rpm, $5 \mathrm{~min}$ ) before determination of total cellular glutathione using a commercial glutathione assay kit (Sigma, United States) according to manufacturers' instructions. Briefly, cell pellets were deproteinized in 5-sulfosalicylic acid (SSA) solution (5\%), vortexed and snap-freezed (3 times in total) before centrifugation (1,500 rpm, $5 \mathrm{~min})$. Supernatants were transferred to clean tubes and stored on ice until analysis. $10 \mu \mathrm{l}$ from each sample was applied to a 96-well plate in separate wells in duplicates and mixed together with $150 \mu \mathrm{l}$ reaction mixture containing $95 \mathrm{mM}$ potassium phosphate buffer ( $\mathrm{pH} \quad 7), \quad 0.95 \mathrm{mM}$ EDTA, $0.031 \mathrm{mg} / \mathrm{ml}$ DTNB, 0.115 units $/ \mathrm{ml}$ glutathione reductase and $0.24 \% 5$-sulfosalicylic acid. Finally, $50 \mu \mathrm{l}$ of NADPH solution $(0.16 \mathrm{mg} / \mathrm{ml}$, resulting in final concentration of $0.038 \mathrm{mg} / \mathrm{ml}(48 \mu \mathrm{M}) \mathrm{NADPH})$ was added to each well and mixed. Immediately after mixing, a kinetic read was performed in $1 \mathrm{~min}$ intervals for $5 \mathrm{~min}$ at $412 \mathrm{~nm}$ using a spectrophotometric plate reader in order to detect the formation of the yellow product 5-thio-2-nitrobenzoic acid (TNB).

\section{Glutamate/Glutamine Determination}

For glutamate/glutamine detection, AGS cells were seeded in 24well plates $\left(1.0 \times 10^{4}\right.$ cells per well $)$ and incubated over night to attain confluency. The cultures were then treated with PEITC $(10-30 \mu \mathrm{M})$ and AITC $(50-200 \mu \mathrm{M})$ for $2-24 \mathrm{~h}$ in defined DMEM containing dialyzed FBS before samples were collected and analyzed for glutamate and glutamine content. Determination of glutamate/glutamine was performed using a detection kit (Sigma, United States) following the manufacturers' instructions. Briefly, from each sample to be analyzed, one sample was prepared for estimating endogenous glutamate, and one sample was prepared for estimating endogenous glutamate and glutamate converted from glutamine based on an initial deamination reaction catalyzed by glutaminase of the samples. All samples were then mixed with glutamic dehydrogenase which generates $\alpha$-ketoglutarate and converts $\mathrm{NAD}^{+}$to $\mathrm{NADH}$ which was detected spectrophotometrically at $340 \mathrm{~nm}$. Glutamate content was then calculated using a standard curve, whereas glutamine content was calculated by subtracting the endogenous glutamate concentration from the total concentration of endogenous glutamate and glutamine-derived glutamate.

\section{Spheroid 3D Culture}

AGS cells were seeded in 96-well plates (1,500 cells per well) with U-shaped bottoms with surface that prevents cells from attaching to the surface (Sumitomo Bakelite Co. Ltd., Japan). The cells were then incubated for 1 day to allow the cells to generate a spheroidlike structure before these spheroids were treated with PEITC $(0-50 \mu \mathrm{M})$ for $48 \mathrm{~h}$. After treatment, proliferation was assayed as described above.

\section{Western Blot}

Western Blot from whole cell extract was performed in order to investigate the presence of protein p53. Cell extracts were prepared using ice-cold RIPA cell lysis buffer (Pierce) containing $0.1 \%$ MG132 Proteasome inhibitor (Cayman Chemical), 1\% Protease inhibitor cocktail (Sigma Aldrich) and 10\% PhosStop phosphatase inhibitor Cocktail (Roche). Bicinchoninate protein quantification (BCA) assay (Nacalai Tesque) was performed in order to determine protein concentrations in the cell lysates prior to SDS PAGE. Samples were denatured in sample buffer (4x) (NuPAGE LDS, Novex, Life Technologies, $\mathrm{pH}$ 8.4) with 5\% 2-mercaptoethanol at $100^{\circ} \mathrm{C}$ for $10 \mathrm{~min}$. Five microgram of protein or molecular weights marker were loaded into the lanes on the SDS PAGE gel and run in MOPS running buffer (NuPAGE, Life Technologies, $\mathrm{pH}$ 7.7) for $5 \mathrm{~min}$ at $150 \mathrm{~V}$ followed by $40 \mathrm{~min}$ at $200 \mathrm{~V}$. After electrophoresis, gels were blotted onto polyvinylidene difluoride (PVDF) membranes in NuPAGE transfer buffer (Life Technologies). Block ACE solution (DS Pharma Biomedical) was used to block the membrane for $1 \mathrm{~h}$ at room temperature. Primary antibody mouse monoclonal anti human p53 clone DO-1 (1:200, Santacruz: sc-126) was added to the membrane and incubated overnight at $4^{\circ} \mathrm{C}$. Mouse monoclonal anti- $\beta$-actin clone, which recognize $\beta$-actin, was used as internal standard. The membrane was washed in tris-buffered saline with $0.5 \%$ Tween 20 (TBST) followed by incubation with secondary antibody anti-mouse IgG HRP-linked whole Ab sheep (1:500) (GE Healthcare: NA931)/AntiRabbit IgG, HRP-linked whole Ab donkey (1:500) (GE Healthcare: NA934) for $1 \mathrm{~h}$ at room temperature. Finally, chemiluminescence capturing using Clarity Western ECL substrate (Bio-RAD) was applied, and images were acquired using a ImageQuant LAS 500 system (GE Healthcare). Quantification of p53 band area was performed in Image studio Lite (LI-COR Biosciences).

\section{Statistical Analysis}

Values are expressed as means \pm SEM in in vivo experiments. Pairwise comparisons between experimental groups were done using one-way ANOVA with Dunnett's test (1-sided) or student's 

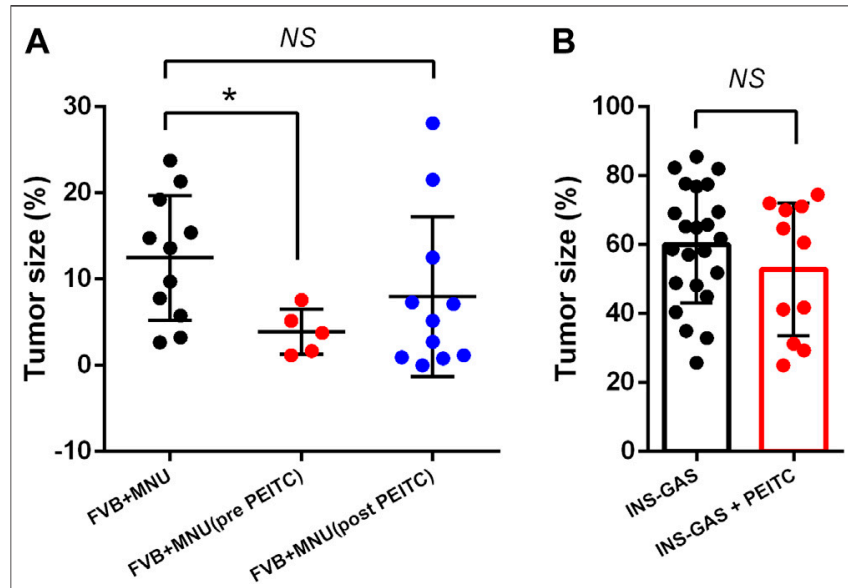

FIGURE 1 | Tumor size of gastric cancer in mice that completed the study period of 45-50 weeks. FVB mice received MNU for 10 weeks $(n=11)$ or MNU together with PEITC (3-5 $\mu \mathrm{mol}$ PEITC/g diet) for 10 weeks $(n=5)$ or post MNU treatment $(n=11)$ (A) and in INS-GAS mice with or without PEITC (3-5 $\mu \mathrm{mol}$ PEITC/g diet) for 10 weeks (B). Mean \pm SEM. Tumor size expressed as volume density (\% of glandular area occupied by tumor). ANOVA + Dunnett's test (1-tailed) in (A), student $t$-test in (B). * $p<0.05$; NS, not significant; PEITC, phenethyl isothiocyanate; $\mathrm{MNU}, \mathrm{N}$-methyl-N-nitrosourea.

t-test between INS-GAS mouse GC tumors with $v s$. without PEITC. In in vitro experiments, cell proliferation is represented by means of $n=3-6$ replicates/treatment $\pm \mathrm{SD}$. $\mathrm{IC}_{50}$ values were calculated from sigmoidal regression curve fitting using variable slope on normalized response from log (10)-transformed x-values (GraphPad Prism v.6). Standard deviation (SD) values (\%) were omitted from cultures with $98 \%$ or higher inhibited growth as these yielded non-representatively high SD values. Cell cycle distribution was analyzed using one-way ANOVA on normally distributed data with Dunnett's 2-sided post hoc test $v$ s. control groups. All tests were with a significance cutoff of $p<0.05$.

\section{RESULTS}

Two mouse models of gastric cancer were used, i.e., MNUinduced gastric cancer (MNU mice) and genetically engineered spontaneously gastric cancer (INS-GAS mice). Body weight of mice with or without PEITC increased due to aging of the mice but was not affected by PEITC treatment during the period of experiment (10 weeks). Tumour size of gastric cancer was significantly reduced by PEITC when given during $\mathrm{MNU}$ but neither after MNU, nor in INS-GAS mice (Figures 1A,B).

To demonstrate the cytotoxicity of ITCs in gastric cancer, four human gastric carcinoma cell lines were used; MKN45, AGS, MKN74 and KATO-III. Aromatic PEITC, BITC or aliphatic AITC resulted in a time and dose-dependent inhibition of cell proliferation (Figures 2A-E). The aromatic ITCs displayed a higher potential in inhibiting cell proliferation in both MKN45 and AGS compared to AITC. The MKN74, MKN45 and KATOIII cells proved to be more tolerant to ITC-treatment than the AGS cells in terms of $\mathrm{IC}_{50}$-values. All cell lines showed alterations in cell morphology by ITC-treatments with a gradual increase in non-confluent cells with increasing ITC-doses as demonstrated by PEITC-treated AGS cells (Figure 2F). A spheroid 3D culture of AGS cells treated with PEITC for 24 and $48 \mathrm{~h}$ showed decreased growth upon increasing doses (Figure 2G).

Due to the electrophilic central $\mathrm{C}$-atom in the reactive $-\mathrm{N}=\mathrm{C}=\mathrm{S}$ group, ITCs are able to antagonize multiple targets including glutathione. We therefore next examined the GSH concentration upon PEITC and AITC treatment. GSH depletion was both time- and dose-dependent in AGS cells (Figures 3A,B). Additionally, the synthetic amino acid Buthionine sulfoximine (BSO) depleted GSH in time- and dose-dependent manner (Figure 3C).

Reflected by the glutathione cycle, there are close relationships between glutathione and the levels of glutamine and glutamate in the cell-pool important for redox homeostasis. We next investigated the ratio between glutamine and glutamate after PEITC. PEITC increased the ratio of glutamine/glutamate in a dose-dependent manner, and furthermore inhibited cell proliferation in glutamine-reduced medium in a concentration-depended manner (Figures 4A,B).

The GSH-pool is an important factor for the cancer cells to maintain redox homeostasis. By depleting cells of glutathione, we hypothesized that ITCs would enhance the in vitro cytotoxicity of cisplatin. To investigate the potential effects of ITCs, AGS and MKN45 cells were pretreated with PEITC, BITC or AITC for 1, 3 or $24 \mathrm{~h}$ followed by cisplatin or 5-FU treatment for $48 \mathrm{~h}$ (Figures 5A-E). Pretreatment with $20 \mu \mathrm{M}$ PEITC in MKN45 cells for $1 \mathrm{~h}$ lowered the $\mathrm{IC}_{50}$ of cisplatin by 2.7 -fold, while pretreatment for $3 \mathrm{~h}$ lowered the $\mathrm{IC}_{50}$ of cisplatin 7-fold. After $24 \mathrm{~h}$, the reduction in $\mathrm{IC}_{50}$ was 8.5 -fold (Figure 5A, third panel). Pre-treatment with $20 \mu \mathrm{M}$ PEITC in AGS cells showed 10-fold reduction after $1 \mathrm{~h}$ (Figure 5B). A similar observation was made for the BITC compound, where $20 \mu \mathrm{M}$ BITC showed 4.6 and 5.7-folds reductions in $\mathrm{IC}_{50}$ after 1 and $24 \mathrm{~h}$, respectively (Figure 5C). The aliphatic AITC failed to induce the synergistic effects with cisplatin, only lowering the $\mathrm{IC}_{50}$ by 1.3 fold after $3 \mathrm{~h}$ or even showing increased $\mathrm{IC}_{50}$ upon pretreatment (1 and $24 \mathrm{~h}$, Figure 5D). Substituting cisplatin by $5-\mathrm{FU}$ did not achieve the same inhibition using PEITC (Figure 5E).

Simultaneous treatments with PEITC $(2.5 \mu \mathrm{M})$ and cisplatin at increasing doses showed no additional inhibitory effect or even had antagonistic effect as reflected in increased $\mathrm{IC}_{50}$ values when PEITC was added (Figures 6A,B).

Cell cycle distribution of KATO-III cells upon 12 and $24 \mathrm{~h}$ treatments with PEITC resulted in $\mathrm{G}_{2} / \mathrm{M}$ phase arrest (Figure 7A). However, when treated with 0,5 or $10 \mu \mathrm{M}$ PEITC together with 0,25 or $50 \mu \mathrm{M}$ cisplatin, a decrease in $G_{1}$ phase was accompanied by increase in $G_{2} / M$ phase and slight increase in apoptotic cells (reflected by sub $G_{1} / G_{0}$ phase increase) (Figure 7B). Treatment of AGS cells with 0 or $5 \mu \mathrm{M}$ PEITC for $24 \mathrm{~h}$ showed increased level of protein p53 as determined by Western Blot (Figures 7C,D).

\section{DISCUSSION}

Long-term exposure to $H$. pylori is associated with progression of precancerous lesions in the stomach and infected individuals may 
<smiles>C=CCN=C=S</smiles>

B
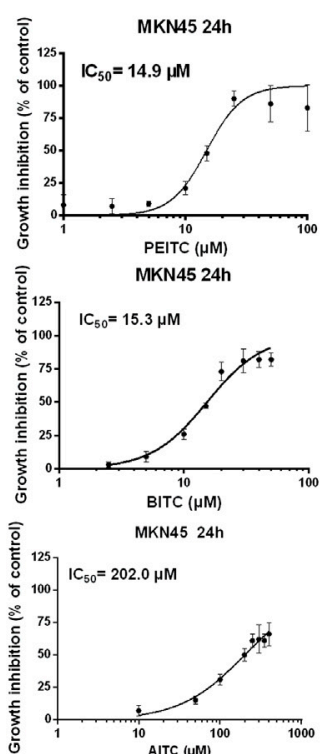

D

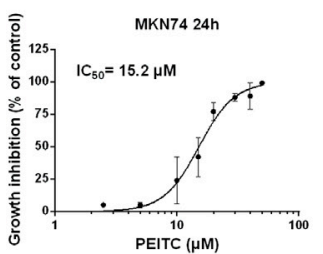

MKN45
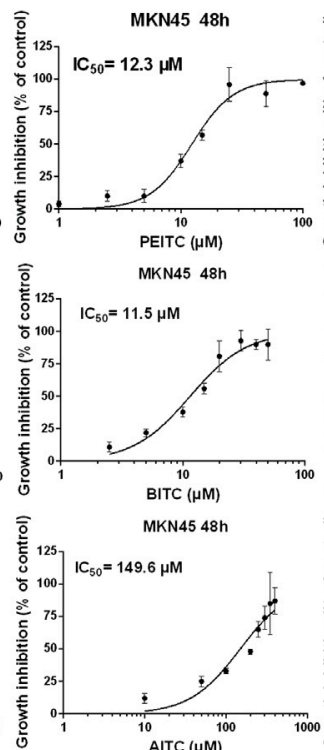

MKN74

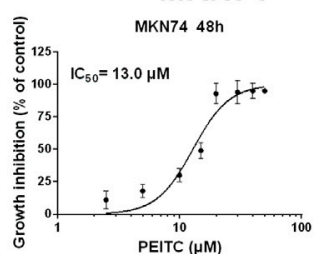

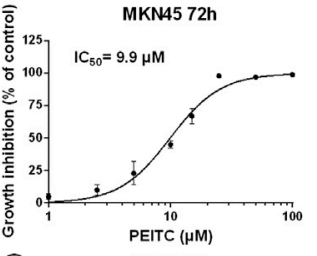
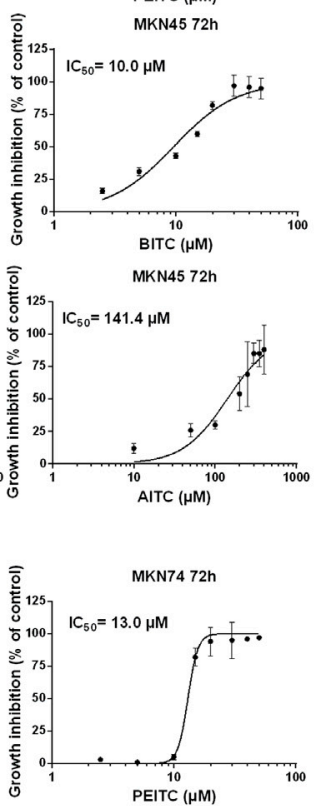

C
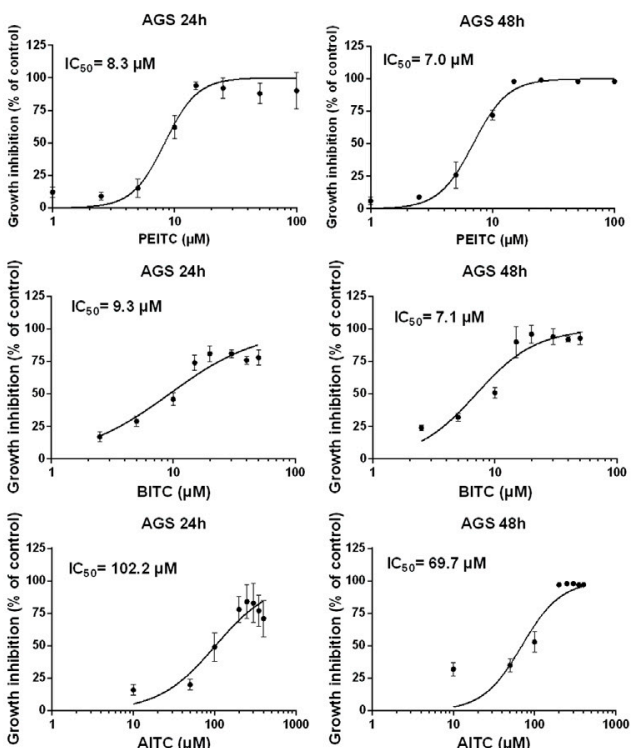

KATO-III
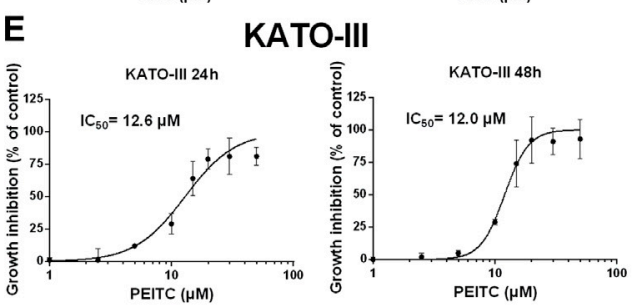

F AGS

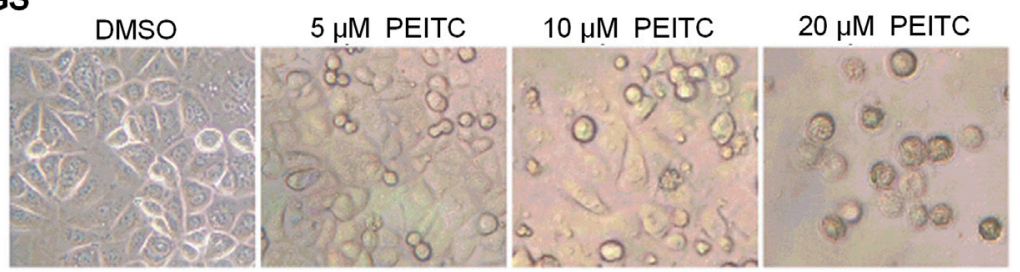

\section{G AGS}
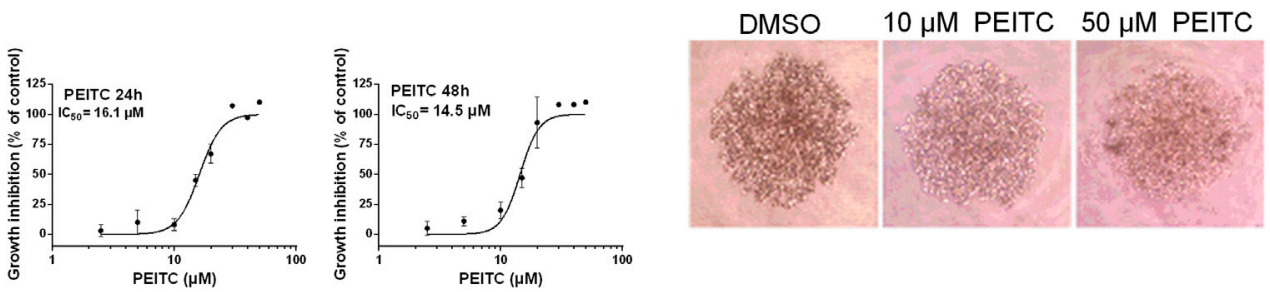

FIGURE 2 | Chemical structures of ITCs (A) and proliferation dose-response curves of gastric cancer cell lines MKN45 (B) and AGS (C) when treated with PEITC $(1-100 \mu \mathrm{M})$, BITC $(2.5-50 \mu \mathrm{M})$ and AITC $(10-400 \mu \mathrm{M})$ for 24,48 and $72 \mathrm{~h}$ in medium containing $1.0 \mathrm{~g} / \mathrm{L}(5.6 \mathrm{mM})$ glucose and $0.584 \mathrm{~g} / \mathrm{L}(4 \mathrm{mM})$ glutamine. Values represent means of $n=3-6$ replicates relative to vehicle control $(0.1 \% \mathrm{DMSO})$, and $\mathrm{IC}_{50}$ values were calculated from the logistic sigmoidal regression curves shown. Standard deviation (SD) values were omitted from cultures with $98 \%$ or higher inhibited growth as these yielded non-representatively high SD values. Proliferation dose-response curves of gastric cancer cell lines MKN74 and KATO-III when treated with PEITC (1-50 $\mu$ M) (D, E). Morphology of AGS cells affected by ITC-treatments (F). Proliferation and morphology of spheroid 3D cultures of AGS cells treated with PEITC for 24-48 h (G). PEITC, phenethyl isothiocyanate; BITC, benzyl isothiocyanate; AITC, allyl isothiocyanate; DMSO, dimethylsulfoxide. 


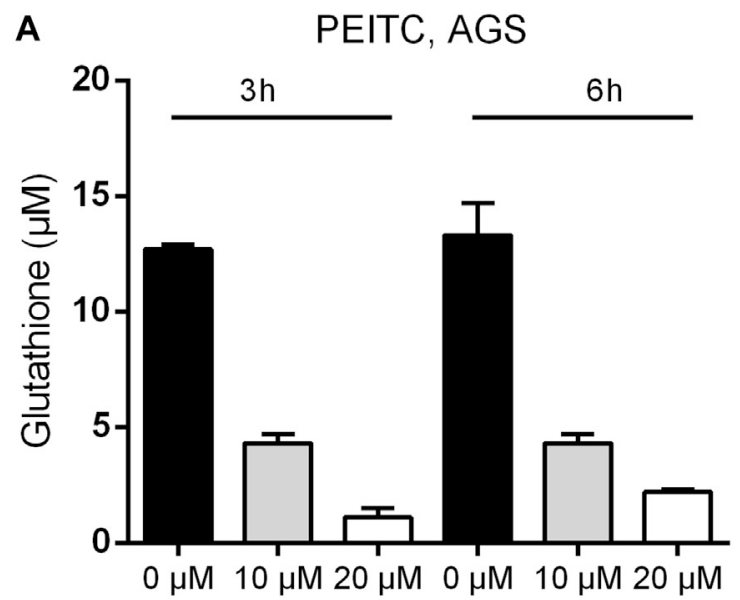

B AITC, AGS

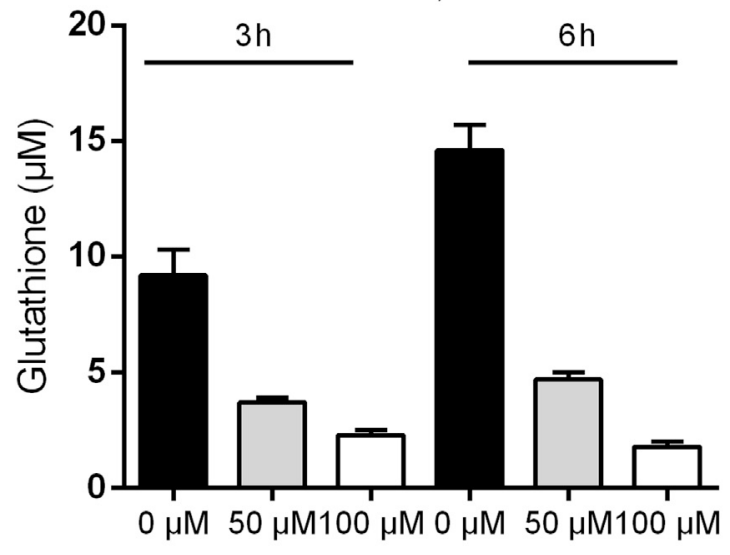

C BSO, AGS $4 \mathrm{~h}$

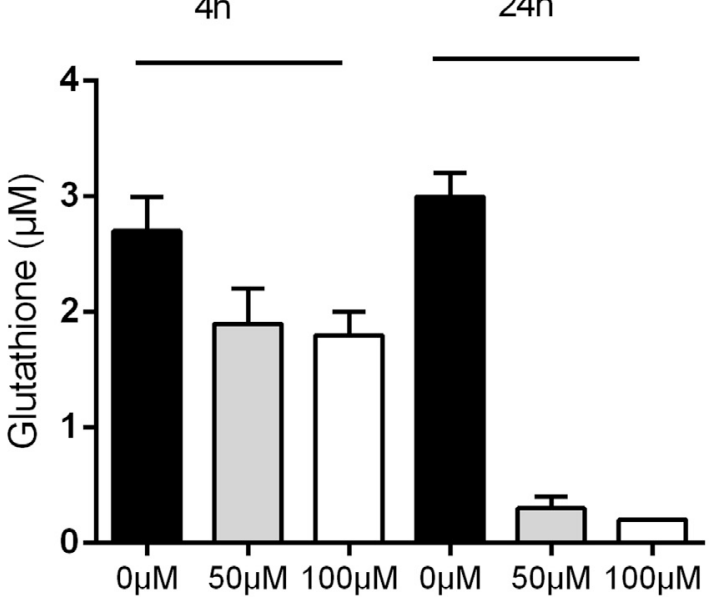

FIGURE 3 | Glutathione concentration upon 3 and $6 \mathrm{~h}$ treatments with PEITC (A) or AITC (B) on AGS cells and upon 4 and $24 \mathrm{~h}$ of treatment with BSO (C) on AGS cells. Mean + SD of $n=4$ replicates/treatment. PEITC, phenethyl isothiocyanate; AITC, allyl isothiocyanate; BSO, Buthionine sulfoximine.

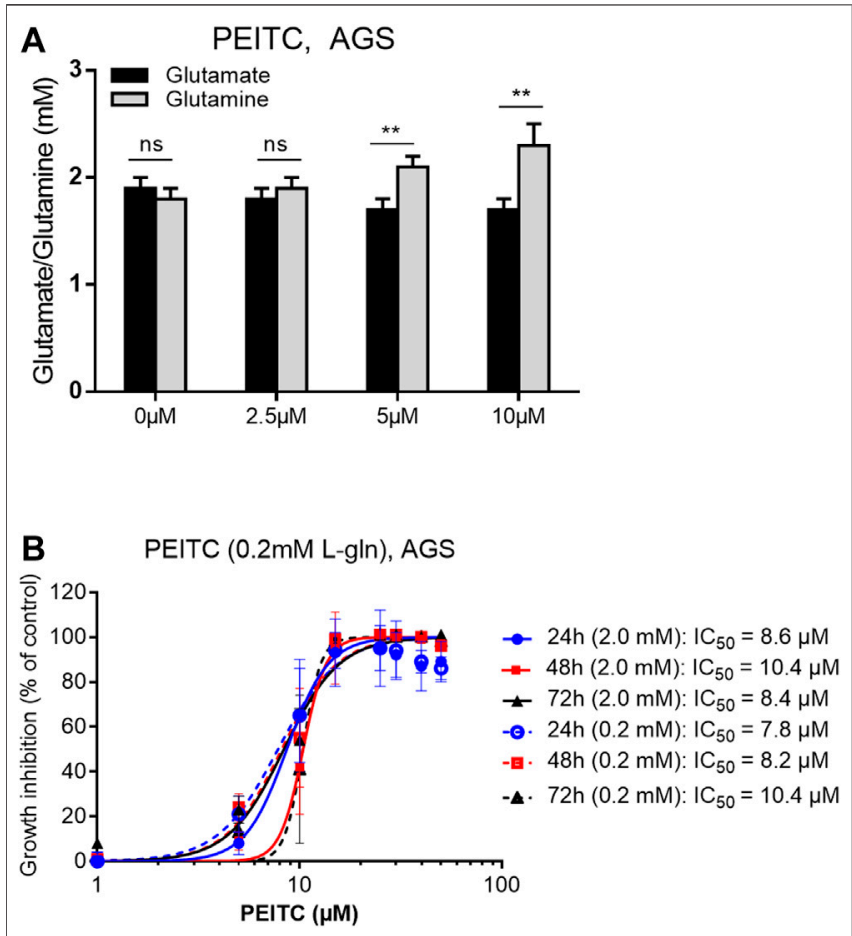

FIGURE 4 | Glutamate/glutamine determination upon $6 \mathrm{~h}$ treatments with $0,2.5,5$ or $10 \mu \mathrm{M}$ PEITC on AGS cells (A). PEITC treatment in L-glutamine-reduced $(\times 10)$ DMEM medium (B). Mean \pm SD. Paired $t$-test in (A). ${ }^{* *} p<0.01$; ns, not significant; PEITC, phenethyl isothiocyanate; L-gln, L-glutamine.

benefit from successful $H$. pylori eradication, and populationbased chemopreventive strategy of $H$. pylori eradication is still under the development (Tan and Wong, 2013; Mera et al., 2018). Other strategies using drugs, such as non-steroidal antiinflammatory drugs and statins, have also been suggested (Ford, 2011). In the present study, we found the chemopreventive effects by PEITC in chemically induced (MNU) animal model of gastric cancer. Interestingly, the chemopreventive effects were neither seen when PEITC was given after the tumor initiation by MNU nor in genetically induced (INS-GAS) gastric cancer. Thus, it is unlikely that PEITC interacts directly with MNU on one hand, but on the other hand, PEITC may act on gastric epithelial cells to prevent the initiation of tumorigenesis as it has been suggested that PEITC induce apoptosis, inhibits cell cycle progression and inhibits angiogenesis (Mitsiogianni et al., 2019). It is known that the regulation of apoptosis by ITC is achieved primarily through mitochondrial cytochrome $c$ release, regulation of the Bcl-2 family, MAPK signaling and subsequent activation of caspases, responsible for the initiation and execution of apoptosis. Specifically, AITC and phenyl-ITC (PITC) inhibit TNF (extrinsic apoptosis), generating a mycelial inhibition for several months, while BITC and PEITC induce a cytochrome $c$ release-dependent type of apoptosis from mitochondria (intrinsic apoptosis) that generates a mycelial inhibition that lasts only for a 

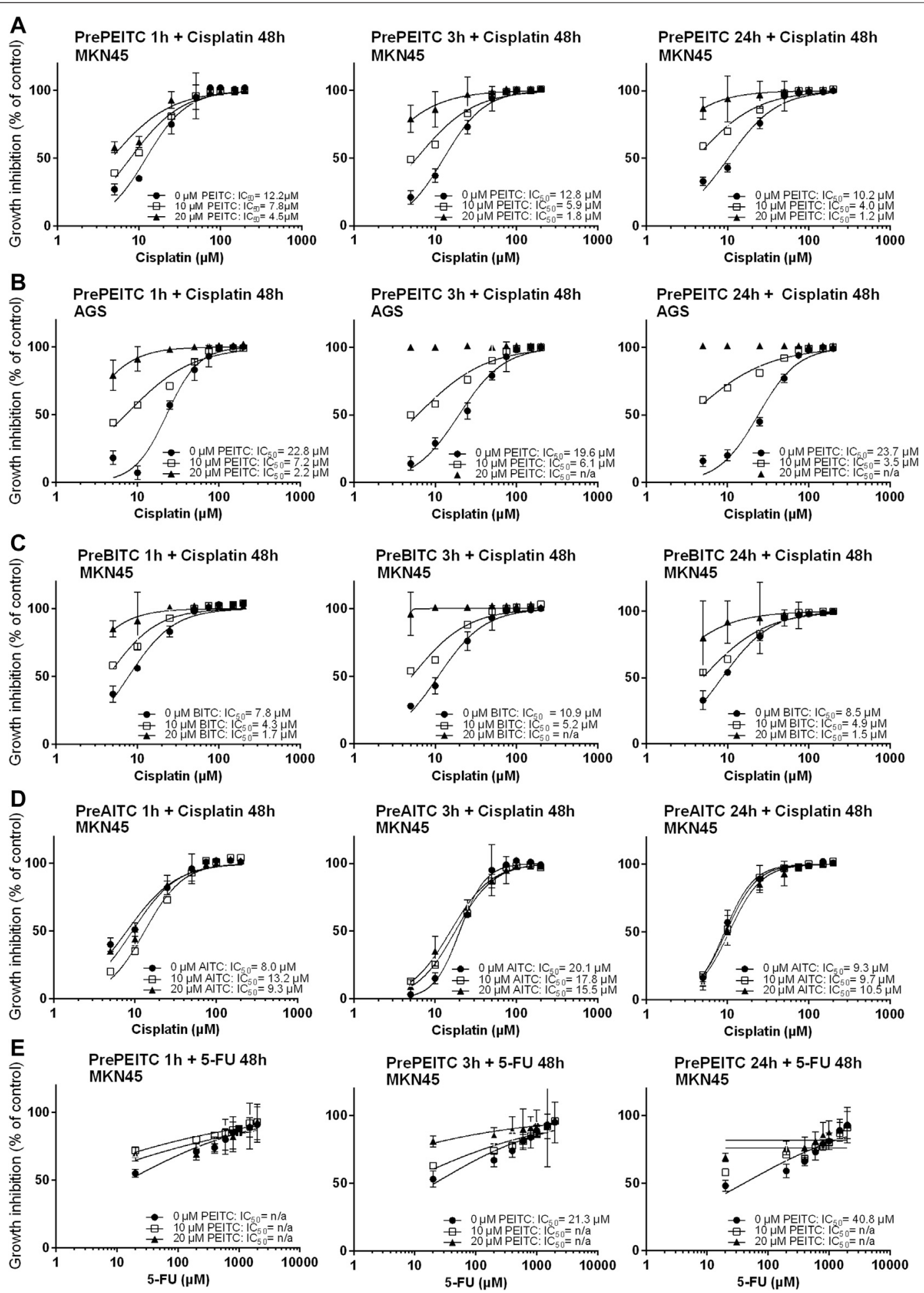

FIGURE 5 | Inhibition of proliferation (relative to vehicle control, 3\% PBS) in cell cultures of MKN45 pre-treated with 10 and $20 \mu \mathrm{M}$ PEITC for 1, 3 and $24 \mathrm{~h}$ before treated with 5-200 $\mu \mathrm{M}$ Cisplatin for $48 \mathrm{~h}$ (A-E). (B, C) same as (A) but with pre-treatment with BITC or AITC instead of PEITC, respectively. (D) same as in (A) using AGS cells instead of MKN45. (E) same as in (A) but treating cells with 5-fluorouracil for $48 \mathrm{~h}$ instead of cisplatin following pre-treatment with PEITC. Values represent mean of $n=3-6$ replicates. SD values were omitted from cultures with $98 \%$ or higher inhibited growth as these yielded non-representatively high SD values. PEITC: phenethyl isothiocyanate; BITC, benzyl isothiocyanate; AITC, allyl isothiocyanate. 


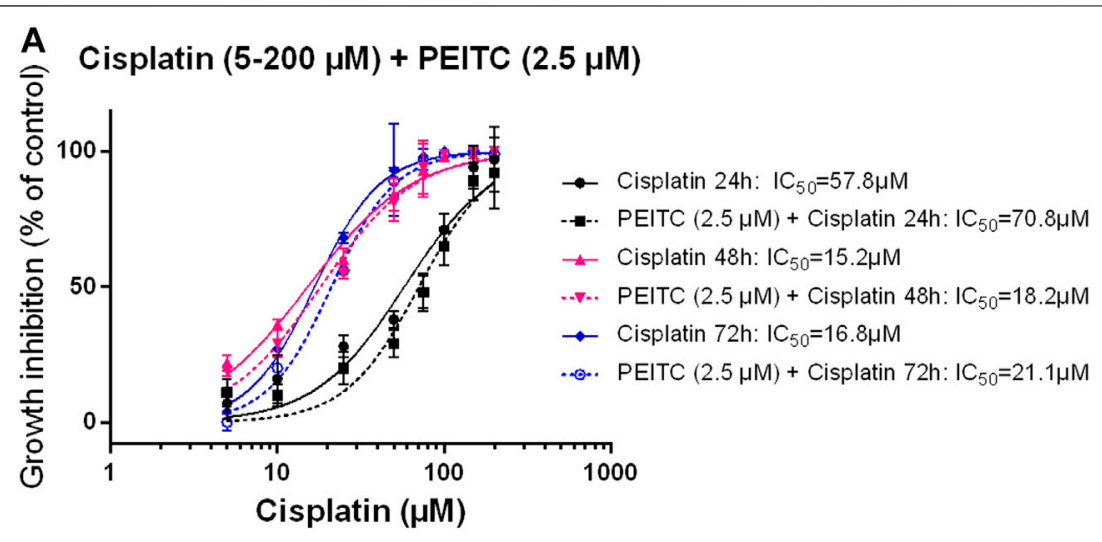

B PEITC $(2.5-50 \mu \mathrm{M})+$ Cisplatin $(25 \mu \mathrm{M})$

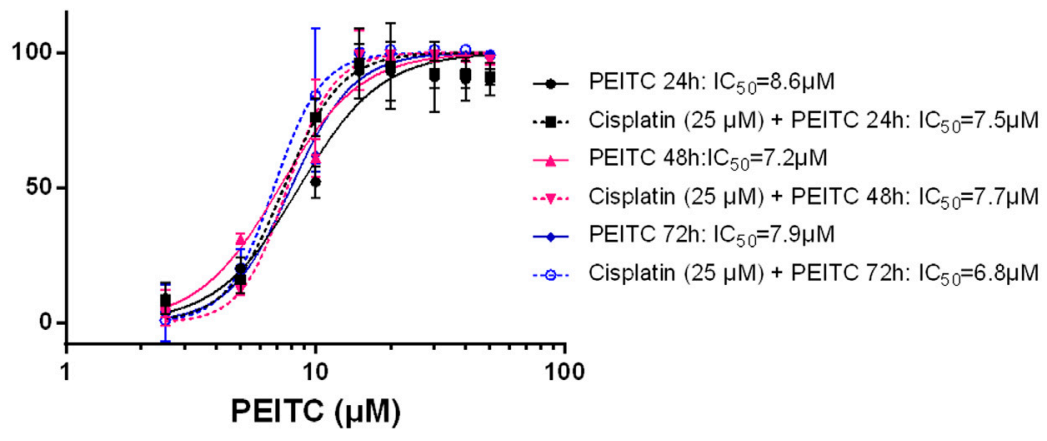

FIGURE 6 | Simultaneous treatment with PEITC and Cisplatin as different concentrations of cisplatin (A) and different concentrations of PEITC (B). Mean \pm SD. PEITC, phenethyl isothiocyanate.

few days. The differences in the fungistatic effect of ITC are possibly due to the type of apoptosis induced. It appears that significant portion of the chemopreventive effects of ITCs might be associated with the inhibition of the metabolic activation of carcinogens by cytochrome P450s (Phase I), coupled with strong induction of Phase II detoxifying and cellular defensive enzymes. Inductions of Phase II cellular enzymes are largely mediated by the antioxidant responsive element (ARE), which is regulated by the transcriptional factor ( $\mathrm{Nrf2}$ ). Additional potent regulatory mechanisms of Nrf2 include the different signaling kinase pathways (MAPK, PI3K, PKC and PERK) as well as other non-kinase dependent mechanisms. Moreover, apoptosis and cell cycle perturbations appear to be yet another potential chemopreventive mechanisms elicited by ITCs, especially with respect to the effects on pre-initiated or initiated tumor cells. Finally, modulation of other critical signaling mediators, including the NF- $\mathrm{KB}$ and $\mathrm{AP}-1$ by a wide array of chemopreventive agents including ITCs might also contribute to the overall chemopreventive mechanisms (Keum et al., 2004).

Although surgery-related outcomes for treatment of gastric cancer, e.g., minimally invasive surgery techniques, continue to improve, the best regimen of either mono- or combination chemotherapy treatments still needs to be improved (Leiting and Grotz, 2019). In fact, the survival benefit of combinations of 5-fluorouracil (5-FU) with leucovorin, etoposide, methotrexate, doxorubicin, epidoxorubicin, cisplatin or oxaliplatin has been demonstrated (Sjoquist and Zalcberg, 2015). The results of the present study showed that there were time- and dose-dependent proliferative inhibitions by PEITC, BITC or AITC in vitro using the human cancer cell lines MKN45, AGS, MKN74 and KATO-III which were derived from intestinal and diffuse types of gastric carcinoma. Furthermore, the results of the present study showed that PEITC depleted intracellular levels of GSH and induced $\mathrm{G}_{2} / \mathrm{M}$ arrest. It is well established that ITCs conjugate with GSH which is a linear tripeptide of L-glutamine, L-cysteine, and glycine. GSH is the main antioxidant metabolite in the cell and provides electrons for enzymes such as glutathione peroxidase, which reduce $\mathrm{H}_{2} \mathrm{O}_{2}$ to $\mathrm{H}_{2} \mathrm{O}$. GSH is crucial for cell proliferation, cell cycle progression and apoptosis and to protect cells from toxic insult by detoxifying toxic metabolites of drugs and ROS (Aquilano et al., 2014; Diaz-Vivancos et al., 2015). The results of the present study showed that intracellular GSH depletion upon PEITC and AITC treatment was both timeand dose-dependent, suggesting gastric cancer are susceptible to glutathione depletion. In fact, it was also reported that combined targeting of the epidermal growth factor receptor effector AKT and the glutathione antioxidant pathway mimicked Nrf2 ablation to potently inhibit pancreatic cancer, representing a promising synthetic lethal strategy for treating pancreatic cancer (Chio et al., 2016). This was in line with the 


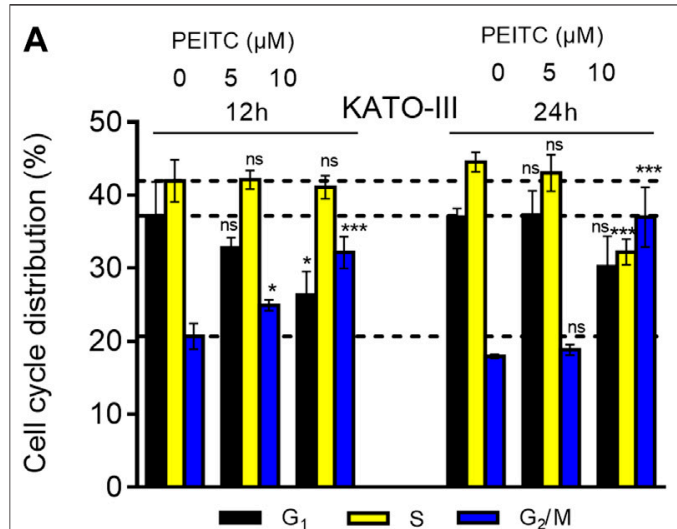

B

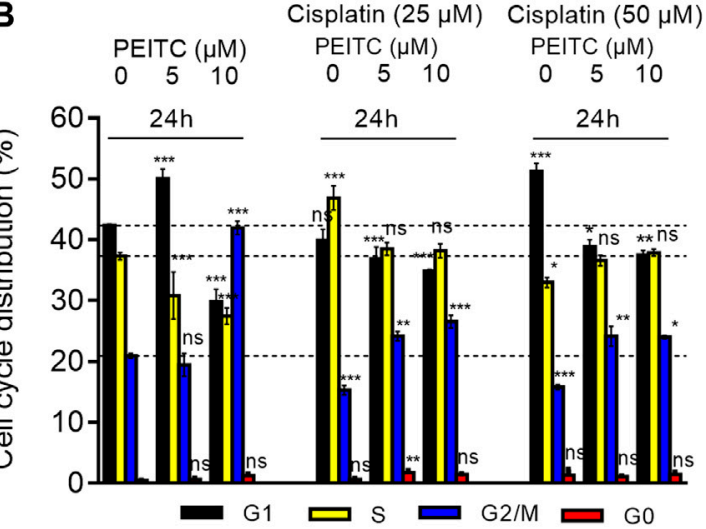

C
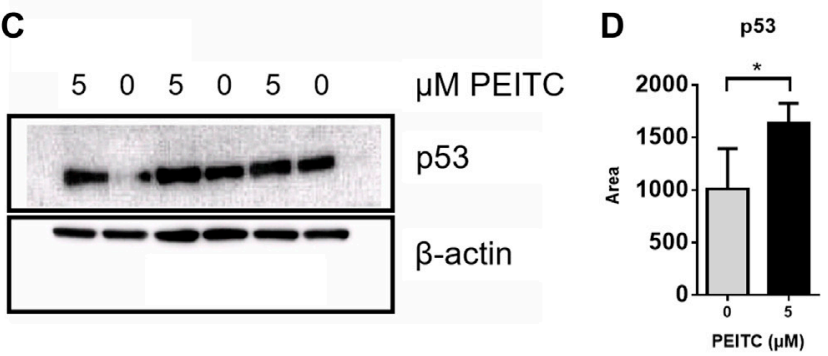

FIGURE 7 | Cell cycle analysis of PEITC (A) and PEITC + cisplatin (B) in KATO-III cells. Analyzed using FACS Canto cell cycle sorter with 20,000 cell reads/sample. Distribution is derived from histograms in FACS Diva software. Mean \pm SD of $n=3$ replicates/treatment. ANOVA with Dunnett's test (2sided) vs. control groups was used. Western blot assessment of proteins p53 and $\beta$-actin (control) in response to PEITC were included in triplicates (C). p53 band area were quantified in Image Studio Lite (D). Bars represent means \pm SD. Independent samples $t$-test (one-tailed) between 0 and $5 \mu \mathrm{M}^{*}: p<0.05$.

results of the present study showing that the synergistic effect of PEITC took place when it was given prior to cisplatin but not simultaneously with cisplatin, as it needs to deplete the intracellular pool of glutathione in order to achieve cell cycle arrest in response to cisplatin. Of note, the results of the present study also showed that pretreatment with PEITC could enhance the cytotoxicity of cisplatin but not of 5-FU. This effect should be explained by the different mechanisms of action between cisplatin (forming DNA crosslinks) and 5-FU (inhibiting thymidylate synthase) (Larionova et al., 2019). It would be of interest to investigate further the effects of PEITC in combination with different chemotherapeutic agents (including cisplatin, 5-FU, paclitaxel, gemcitabine, and trabectedin) that have different mechanisms of action in order to explore the mechanism of PEITC and to find the best combination therapy.

Interference of ITC with microtubules have also been established as a contributor to cells stagnating in the $G_{2}$ / M-phase (Mi et al., 2009; Øverby et al., 2014). Buthionine sulfoximine (BSO), a synthetic amino acid, is an inhibitor of GSH synthesis on intracellular GSH levels (Griffith and Meister, 1979; Aldini et al., 2018). The results of the present study showed that BSO depleted GSH in a time- and dose-dependent manner and that PEITC-treatment altered the intracellular glutamine/ glutamate ratio, providing a possible link between ITCs and amino acid metabolism. We suggested that the increase in glutamine but not glutamate levels shown in the present study could be attributed to compensatory mechanisms towards GSH replenishment in the cell when GSH level decreases. Indeed, a previous report has found that glutamine consumption correlated with glutathione excretion (Sappington et al., 2016).

It is known that elevated GSH levels are associated with tumor cell resistance to alkylating agents and platinum compounds (Estrela et al., 2006; Ortega et al., 2011; Bansal and Simon, 2018). Elevated GSH levels are observed in various types of tumors (Calvert et al., 1998). It has been suggested that high intracellular GSH level increases the antioxidant capacity and is thus conferring therapeutic resistance to cancer cells through the ability to resist oxidative stress which is a critical component of cisplatin cytotoxicity (Yu et al., 2018). We hypothesized that ITCs would enhance the cytotoxicity of cisplatin by depleting cells of glutathione, and indeed we found that PEITC and BITC but not AITC sensitized the gastric cancer cells to cisplatin. Conceivably, when the cell is depleted of GSH and oxidative stress is introduced using cytotoxic agents, a collapse in the antioxidant system eventually leads to cell death. Although reduction in GSH is proposed as a possible mechanism in the present study, it should be noticed that ITCs at sufficiently low doses might actually increase GSH levels as a consequence of ROS induction. Di Pasqua and colleagues described reduction of GSH as a less likely explanation to potentiating lung cancer cells by ITC but accredited the binding to tubulin as a more plausible explanation (Di Pasqua et al., 2010). In fact, PEITC and cisplatin have been co-administered using liposomal nanoparticles for treatment of non-small cell lung cancer (Sun et al., 2019). The efficacy potentiating of ITCs on existing chemotherapy has also been studied in cancers such as Barrett esophageal adenocarcinoma (Qazi et al., 2010), ovarian carcinoma (Stehlik et al., 2010), non-small cell lung carcinoma (Di Pasqua et al., 2010), prostate cancer (Xiao and Singh, 2010) and cervical cancer cells (Wang et al., 2011) in combination with drugs such as paclitaxel, MST-312, GRN163L, cisplatin and docetaxel. Thus, the results of the present study provide additional evidence in gastric cancer. The results of the present study also showed that PEITC induced cell cycle arrest in $\mathrm{G}_{2} / \mathrm{M}$ phase which was associated with increased $\mathrm{p} 53$ protein 
levels. p53 is one of the classical tumor suppressor genes that interferes with cell transformation events and plays a critical role in cell cycle control and induction of apoptosis (Ozaki and Nakagawara, 2011; Bykov et al., 2016; Bykov et al., 2018). It can be elevated in response to genotoxic agents, such as ionizing radiation, UV light, or chemicals. It has been shown that p53 elevation was required for PEITC-induced apoptosis (Huang et al., 1998).

However, some limitations of the present study should be noticed. First, we did not include additional animal groups, e.g., normal mice, MNU and INS-GAS mice that should be treated with PEITC or cisplatin alone and combination of PEITC plus cisplatin to explore the possibilities that PEITC may have differential effects on gastric cancer cells compared to normal gastric epithelial cells and that there is likely a synergistic anticancer effect in vivo. In fact, it has been showed that combining AITC with cisplatin reduced tumor volume in a mouse model of human lung cancer (Ling et al., 2015), thus this could also be a promising strategy in gastric cancer. Secondly, we did not investigate the molecular mechanism of action including signaling pathways of ITCs in combination with cisplatin, in gastric cancer cells. Third, we did not perform the combination of denervation and PEITC with or without chemotherapy, as initially planned. Forth, we did not further investigate the possible mechanism by which the only pretreatment with PEITC was effective against NMU-induced gastric cancer, and neither concomitant treatment nor administration of this agent after cancer development (either in NMU or INS-GAS mice) was successful. In addition to preinitiated or initiated tumor cells as a possible target of PEITC (aforementioned), there are other possible hypotheses/ explanations. It has been known that there are different windows for chemoprevention and therapeutic effects during the tumorigenesis from initiation, promotion and progression (Hanahan and Weinberg, 2011; Liu et al., 2015). It is also possible that the anti-cancer agents (e.g., ITCs) exhibit the effect on the initiation phase when given at a low dose and on the progression phase at a high dose. In the present study, PEITC (MW 163.24 g/ $\mathrm{mol}$ ) was given at $3-5 \mu \mathrm{mol} / \mathrm{g}$ diet in mice. Based on the pharmacokinetics of PEITC, the oral administration of PEITC at this dose level would reach a circulation level that is in a similar order of magnitude of $\mathrm{IC}_{50}(15 \mu \mathrm{M})$ in vitro but be a lower order of magnitude in gastric tissue (pmol/mg) (Reimer, 1972; Conaway et al., 1999). Fifth, it is still unclear why the synergistic effect was not obtained when PEITC and cisplatin were given simultaneously in the cell culture model. In fact, we failed to measure GSH levels because of heavily fluctuating potentiating effect. Fluctuating levels of GSH was found across our experiments measuring GSH concentration, where the intracellular GSH levels ranged between 3 and $10 \mu \mathrm{M}$ GSH between experiments, adding to the complexity of GSH's role in the observations. Finally, it should also be noticed that this study was carried out in the mouse models of gastric cancer and in the cell lines derived from human gastric cancer. It would be of interest to study the possible cytotoxic effects of ITCs in normal tissue and/or cell lines derived from normal healthy human stomach, e.g., cell line of HGaEpC, in the future. Taken together, it is still a challenge for future development of food products that contains high levels of edible ITCs for chemoprevention and for being used during chemotherapy in patients with gastric cancer.

It would also be of interest to explore the possible efficacy's potentiating role of ITCs on other therapies, such as targeted therapy and immunotherapy. In fact, combination of ERBB2 antagonist or RARA agonist was reported to be effective synergistic regimens for ERBB2 positive gastric cancer (Xiang et al., 2018). In clinical setting, the treatment options for advanced-stage gastric cancer are limited, despite an approval of two targeted agents, trastuzumab and ramucirumab. Consequently, the overall clinical outcomes for patients with advanced-stage gastric cancer remain poor. Numerous agents that are active against novel targets have been evaluated in the course of randomized trials; however, most have produced disappointing results because of the heterogeneity of gastric cancer (Kumar et al., 2018). Immunotherapy, e.g., immune checkpoint inhibitors (ICIs), has been tested in gastric cancer. Despite having good efficacy and safety profile, ICIs are clinically active only in small subset of patients and therefore, there is a huge unmet need to enhance their efficacy. Indeed, there are several ongoing clinical trials that are exploring the role of ICIs in various gastrointestinal cancers either as single agent or in combination with chemotherapy, radiation therapy, targeted agents or other immunotherapeutic agents, but not yet ITC (Mazloom et al., 2020).

\section{CONCLUSION}

PEITC displayed anti-cancer effects, particularly when given before the tumor initiation, suggesting a chemopreventive effect in gastric cancer, and that aromatic ITCs potentiated the anti-cancer effects of cisplatin, particularly when given before cisplatin, suggesting a possible combination strategy in treatment of gastric cancer.

\section{DATA AVAILABILITY STATEMENT}

The raw data supporting the conclusions of this article will be made available by the authors, without undue reservation.

\section{ETHICS STATEMENT}

The animal study was reviewed and approved by The Norwegian Food Safety Authority (Mattilsynet).

\section{AUTHOR CONTRIBUTIONS}

H-LR: in vitro experiments, all sample/data collection and preparation, data analysis and interpretation, writing manuscript. YK: in vivo Experiments, sample/data collection and preparation, writing manuscript. MN, AMB, and TCW: Project discussion, data interpretation, writing manuscript. DC: Project concept, study idea 
and design, data analysis and interpretation, writing manuscript. C-MZ: Project concept, study idea and design, in vivo experiments, sample collection and preparation, data interpretation, writing manuscript. $\mathrm{A} \varnothing$ : project design, in vivo and in vitro experiments, sample/data collection and preparation, data analysis and interpretation, writing manuscript.

\section{FUNDING}

The research was supported by the Liaison Committee between the Central Norway Regional Health Authority (Helse-Midt Norge RHF), Norwegian University of Science and Technology

\section{REFERENCES}

Aldini, G., Altomare, A., Baron, G., Vistoli, G., Carini, M., Borsani, L., et al. (2018). $\mathrm{N}$-Acetylcysteine as an antioxidant and disulphide breaking agent: the reasons why. Free Radic. Res. 52, 751-762. doi:10.1080/10715762.2018.1468564

Aquilano, K., Baldelli, S., and Ciriolo, M. R. (2014). Glutathione: new roles in redox signaling for an old antioxidant. Front. Pharmacol. 5, 196. doi:10.3389/fphar. 2014.00196

Bansal, A., and Simon, M. C. (2018). Glutathione metabolism in cancer progression and treatment resistance. J. Cell Biol. 217, 2291-2298. doi:10.1083/jcb. 201804161

Bray, F., Ferlay, J., Soerjomataram, I., Siegel, R. L., Torre, L. A., and Jemal, A. (2018). Global cancer statistics 2018: GLOBOCAN estimates of incidence and mortality worldwide for 36 cancers in 185 countries. CA Cancer J. Clin. 68, 394-424. doi:10.3322/caac.21492

Bykov, V. J., Zhang, Q., Zhang, M., Ceder, S., Abrahmsen, L., and Wiman, K. G. (2016). Targeting of mutant $\mathrm{p} 53$ and the cellular redox balance by APR-246 as a strategy for efficient cancer therapy. Front. Oncol. 6, 21. doi:10.3389/fonc.2016. 00021

Bykov, V. J. N., Eriksson, S. E., Bianchi, J., and Wiman, K. G. (2018). Targeting mutant p53 for efficient cancer therapy. Nat. Rev. Cancer 18, 89-102. doi:10. 1038/nrc.2017.109

Calvert, P., Yao, K. S., Hamilton, T. C., and O’Dwyer, P. J. (1998). Clinical studies of reversal of drug resistance based on glutathione. Chem. Biol. Interact. 111-112, 213-224. doi:10.1016/s0009-2797(98)00008-8

Chen, Y., Li, Y., Wang, X. Q., Meng, Y., Zhang, Q., Zhu, J. Y., et al. (2018). Phenethyl isothiocyanate inhibits colorectal cancer stem cells by suppressing Wnt/ $\beta$-catenin pathway. Phytother. Res. 32, 2447-2455. doi:10.1002/ptr.6183

Chio, I. I. C., Jafarnejad, S. M., Ponz-Sarvise, M., Park, Y., Rivera, K., Palm, W., et al. (2016). NRF2 promotes tumor maintenance by modulating mRNA translation in pancreatic cancer. Cell 166, 963-976. doi:10.1016/j.cell.2016.06.056

Chu, W. F., Wu, D. M., Liu, W., Wu, L. J., Li, D. Z., Xu, D. Y., et al. (2009). Sulforaphane induces G2-M arrest and apoptosis in high metastasis cell line of salivary gland adenoid cystic carcinoma. Oral Oncol. 45, 998-1004. doi:10.1016/ j.oraloncology.2009.05.641

Chung, M. Y., Lim, T. G., and Lee, K. W. (2013). Molecular mechanisms of chemopreventive phytochemicals against gastroenterological cancer development. World J. Gastroenterol. 19, 984-993. doi:10.3748/wjg.v19.i7.984

Clarke, J. D., Dashwood, R. H., and Ho, E. (2008). Multi-targeted prevention of cancer by sulforaphane. Cancer Lett. 269, 291-304. doi:10.1016/j.canlet.2008. 04.018

Conaway, C. C., Jiao, D., Kohri, T., Liebes, L., and Chung, F. L. (1999). Disposition and pharmacokinetics of phenethyl isothiocyanate and 6-phenylhexyl isothiocyanate in F344 rats. Drug Metab. Dispos. 27, 13-20.

Conaway, C. C., Yang, Y. M., and Chung, F. L. (2002). Isothiocyanates as cancer chemopreventive agents: their biological activities and metabolism in rodents and humans. Curr. Drug Metab. 3, 233-255. doi:10.2174/1389200023337496

Cunningham, D., Starling, N., Rao, S., Iveson, T., Nicolson, M., Coxon, F., et al. (2008). Capecitabine and oxaliplatin for advanced esophagogastric cancer. $N$. Engl. J. Med. 358, 36-46. doi:10.1056/NEJMoa073149
(NTNU grant no. 46056636/46056928/90061700/90061701), Joint Program of the Medical Faculty of NTNU, the Research Council of Norway, and the Cancer Foundation of St. Olavs Hospital (Kreftfondet ved St. Olavs hospital), the Japan Society for the Promotion of Science (JSPS grant no. 15F14741) and the Scandinavia-Japan Sasakawa Foundation (SJSF).

\section{ACKNOWLEDGMENTS}

We thank Dr. Signe E. Åsberg and Ragni A. Stokland (NTNU) for participating in animal experiments and Dr. Tetsufumi Takahashi (Kitasato University) for assisting on in vitro experiments.

Di Pasqua, A. J., Hong, C., Wu, M. Y., McCracken, E., Wang, X., Mi, L., et al. (2010). Sensitization of non-small cell lung cancer cells to cisplatin by naturally occurring isothiocyanates. Chem. Res. Toxicol. 23, 1307-1309. doi:10.1021/ tx100187f

Diaz-Vivancos, P., de Simone, A., Kiddle, G., and Foyer, C. H. (2015). Glutathione--linking cell proliferation to oxidative stress. Free Radic. Biol. Med. 89, 1154-1164. doi:10.1016/j.freeradbiomed.2015.09.023

Dunn, B. K., Umar, A., and Richmond, E. (2016). Introduction: cancer chemoprevention and its context. Semin. Oncol. 43, 19-21. doi:10.1053/j. seminoncol.2015.11.002

Estrela, J. M., Ortega, A., and Obrador, E. (2006). Glutathione in cancer biology and therapy. Crit. Rev. Clin. Lab Sci. 43, 143-181. doi:10.1080/10408360500523878

Ferlay, J., Shin, H. R., Bray, F., Forman, D., Mathers, C., and Parkin, D. M. (2010). Estimates of worldwide burden of cancer in 2008: GLOBOCAN 2008. Int. J. Cancer 127, 2893-2917. doi:10.1002/ijc.25516

Ferlay, J. S. I., Ervik, M., Dikshit, R., Eser, S., Mathers, C., et al. (2013). GLOBOCAN 2012 v1.0, cancer incidence and mortality worldwide: IARC CancerBase No. 11. Lyon, France: International Agency for Research on Cancer.

Ford, A. C. (2011). Chemoprevention for gastric cancer. Best Pract. Res. Clin. Gastroenterol. 25, 581-592. doi:10.1016/j.bpg.2011.09.002

Griffith, O. W., and Meister, A. (1979). Potent and specific inhibition of glutathione synthesis by buthionine sulfoximine (S-n-butyl homocysteine sulfoximine). J. Biol. Chem. 254, 7558-7560. doi:10.1016/s0021-9258(18)35980-5

Gupta, P., Wright, S. E., Kim, S. H., and Srivastava, S. K. (2014). Phenethyl isothiocyanate: a comprehensive review of anti-cancer mechanisms. Biochim. Biophys. Acta 1846, 405-424. doi:10.1016/j.bbcan.2014.08.003

Hanahan, D., and Weinberg, R. A. (2011). Hallmarks of cancer: the next generation. Cell 144, 646-674. doi:10.1016/j.cell.2011.02.013

Hu, K., and Morris, M. E. (2004). Effects of benzyl-, phenethyl-, and alphanaphthyl isothiocyanates on P-glycoprotein- and MRP1-mediated transport. J. Pharm. Sci. 93, 1901-1911. doi:10.1002/jps.20101

Huang, C., Ma, W. Y., Li, J., Hecht, S. S., and Dong, Z. (1998). Essential role of p53 in phenethyl isothiocyanate-induced apoptosis. Cancer Res. 58, 4102-4106.

Kang, Y. K., Kang, W. K., Shin, D. B., Chen, J., Xiong, J., Wang, J., et al. (2009). Capecitabine/cisplatin versus 5-fluorouracil/cisplatin as first-line therapy in patients with advanced gastric cancer: a randomised phase III noninferiority trial. Ann. Oncol. 20, 666-673. doi:10.1093/annonc/mdn717

Keum, Y. S., Jeong, W. S., and Kong, A. N. (2004). Chemoprevention by isothiocyanates and their underlying molecular signaling mechanisms. Mutat. Res. 555, 191-202. doi:10.1016/j.mrfmmm.2004.05.024

Keum, Y. S., Jeong, W. S., and Kong, A. N. (2005). Chemopreventive functions of isothiocyanates. Drug News Perspect. 18, 445-451. doi:10.1358/dnp.2005.18.7. 939350

Koizumi, W., Narahara, H., Hara, T., Takagane, A., Akiya, T., Takagi, M., et al. (2008). S-1 plus cisplatin versus S-1 alone for first-line treatment of advanced gastric cancer (SPIRITS trial): a phase III trial. Lancet Oncol. 9, 215-221. doi:10. 1016/S1470-2045(08)70035-4

Kumar, V., Soni, P., Garg, M., Kamholz, S., and Chandra, A. B. (2018). Emerging therapies in the management of advanced-stage gastric cancer. Front. Pharmacol. 9, 404. doi:10.3389/fphar.2018.00404 
Larionova, I., Cherdyntseva, N., Liu, T., Patysheva, M., Rakina, M., and Kzhyshkowska, J. (2019). Interaction of tumor-associated macrophages and cancer chemotherapy. Oncoimmunology 8, e1596004. doi:10.1080/2162402X. 2019.1596004

Lawson, A. P., Long, M. J. C., Coffey, R. T., Qian, Y., Weerapana, E., El Oualid, F., et al. (2015). Naturally occurring isothiocyanates exert anticancer effects by inhibiting deubiquitinating enzymes. Cancer Res. 75, 5130-5142. doi:10.1158/ 0008-5472.CAN-15-1544

Leiting, J. L., and Grotz, T. E. (2019). Advancements and challenges in treating advanced gastric cancer in the West. World J. Gastrointest. Oncol. 11, 652-664. doi:10.4251/wjgo.v11.i9.652

Li, Y., Zhang, T., Korkaya, H., Liu, S., Lee, H. F., Newman, B., et al. (2010). Sulforaphane, a dietary component of broccoli/broccoli sprouts, inhibits breast cancer stem cells. Clin. Cancer Res. 16, 2580-2590. doi:10.1158/1078-0432. CCR-09-2937

Li, Y., and Zhang, T. (2013). Targeting cancer stem cells with sulforaphane, a dietary component from broccoli and broccoli sprouts. Future Oncol. 9, 1097-1103. doi:10.2217/fon. 13.108

Ling, X., Westover, D., Cao, F., Cao, S., He, X., Kim, H. R., et al. (2015). Synergistic effect of allyl isothiocyanate (AITC) on cisplatin efficacy in vitro and in vivo. Am. J. Cancer Res. 5, 2516-2530.

Liu, Y., Yin, T., Feng, Y., Cona, M. M., Huang, G., Liu, J., et al. (2015). Mammalian models of chemically induced primary malignancies exploitable for imagingbased preclinical theragnostic research. Quant Imaging Med. Surg. 5, 708-729. doi:10.3978/j.issn.2223-4292.2015.06.01

Lv, H., Zhen, C., Liu, J., and Shang, P. (2020). $\beta$-Phenethyl isothiocyanate induces cell death in human osteosarcoma through altering iron metabolism, disturbing the redox balance, and activating the MAPK signaling pathway. Oxid Med. Cell Longev. 2020, 5021983. doi:10.1155/2020/5021983

Mazloom, A., Ghalehsari, N., Gazivoda, V., Nimkar, N., Paul, S., Gregos, P., et al. (2020). Role of immune checkpoint inhibitors in gastrointestinal malignancies. J. Clin. Med. 9, 2533. doi:10.3390/jcm9082533

Mera, R. M., Bravo, L. E., Camargo, M. C., Bravo, J. C., Delgado, A. G., RomeroGallo, J., et al. (2018). Dynamics of Helicobacter pylori infection as a determinant of progression of gastric precancerous lesions: 16-year followup of an eradication trial. Gut 67, 1239-1246. doi:10.1136/gutjnl-2016-311685

Mi, L., Gan, N., and Chung, F. L. (2009). Aggresome-like structure induced by isothiocyanates is novel proteasome-dependent degradation machinery. Biochem. Biophys. Res. Commun. 388, 456-462. doi:10.1016/j.bbrc.2009.08.047

Mitsiogianni, M., Koutsidis, G., Mavroudis, N., Trafalis, D. T., Botaitis, S., Franco, R., et al. (2019). The role of isothiocyanates as cancer chemo-preventive, chemo-therapeutic and anti-melanoma agents. Antioxidants (Basel) 8, 106. doi:10.3390/antiox8040106

Orditura, M., Galizia, G., Sforza, V., Gambardella, V., Fabozzi, A., Laterza, M. M., et al. (2014). Treatment of gastric cancer. World J. Gastroenterol. 20, 1635-1649. doi:10.3748/wjg.v20.i7.1635

Ortega, A. L., Mena, S., and Estrela, J. M. (2011). Glutathione in cancer cell death. Cancers (Basel) 3, 1285-1310. doi:10.3390/cancers3011285

Øverby, A., Stokland, R. A., Åsberg, S. E., Sporsheim, B., and Bones, A. M. (2015). Allyl isothiocyanate depletes glutathione and upregulates expression of glutathione S-transferases in Arabidopsis thaliana. Front. Plant Sci. 6, 277. doi:10.3389/fpls.2015.00277

Øverby, A., Zhao, C. M., Bones, A. M., and Chen, D. (2014). Naturally occurring phenethyl isothiocyanate-induced inhibition of gastric cancer cell growth by disruption of microtubules. J. Gastroenterol. Hepatol. 29 (Suppl. 4), 99-106. doi:10.1111/jgh.12732

Ozaki, T., and Nakagawara, A. (2011). Role of p53 in cell death and human cancers. Cancers (Basel) 3, 994-1013. doi:10.3390/cancers3010994

Qazi, A., Pal, J., Maitah, M., Fulciniti, M., Pelluru, D., Nanjappa, P., et al. (2010). Anticancer activity of a broccoli derivative, sulforaphane, in barrett adenocarcinoma: potential use in chemoprevention and as adjuvant in chemotherapy. Transl. Oncol. 3, 389-399. doi:10.1593/tlo.10235

Rabben, H.-L., Andersen, G. T., Olsen, M. K., Øverby, A., Ianevski, A., et al. (2021). Neural signaling modulates metabolism of gastric cancer. iScience 24, 102091. doi:10.1016/j.isci.2021.102091
Rabben, H. L., Zhao, C. M., Hayakawa, Y., Wang, T. C., and Chen, D. (2016). Vagotomy and gastric tumorigenesis. Curr. Neuropharmacol. 14, 967-972. doi:10.2174/1570159x14666160121114854

Reimer, F. (1972). Developmental trends in psychiatric hospitals. Offentl. Gesundheitswes. 34 (Suppl. 1), 26-33.

Sappington, D. R., Siegel, E. R., Hiatt, G., Desai, A., Penney, R. B., Jamshidi-Parsian, A., et al. (2016). Glutamine drives glutathione synthesis and contributes to radiation sensitivity of A549 and H460 lung cancer cell lines. Biochim. Biophys. Acta 1860, 836-843. doi:10.1016/j.bbagen.2016.01.021

Sjoquist, K. M., and Zalcberg, J. R. (2015). Gastric cancer: past progress and present challenges. Gastric Cancer 18, 205-209. doi:10.1007/s10120-014-0437-0

Stehlik, P., Paulikova, H., and Hunakova, L. (2010). Synthetic isothiocyanate indole-3-ethyl isothiocyanate (homoITC) enhances sensitivity of human ovarian carcinoma cell lines A2780 and A2780/CP to cisplatin. Neoplasma 57, 473-481. doi:10.4149/neo_2010_05_473

Steward, W. P., and Brown, K. (2013). Cancer chemoprevention: a rapidly evolving field. Br. J. Cancer 109, 1-7. doi:10.1038/bjc.2013.280

Sun, M., Shi, Y., Dang, U. J., and Di Pasqua, A. J. (2019). Phenethyl isothiocyanate and cisplatin Co-encapsulated in a liposomal nanoparticle for treatment of nonsmall cell lung cancer. Molecules 24, 801. doi:10.3390/molecules 24040801

Tan, V. P., and Wong, B. C. (2013). Gastric cancer chemoprevention: the current evidence. Gastroenterol. Clin. N. Am. 42, 299-316. doi:10.1016/j.gtc.2013. 02.001

Tomczyk, J., and Olejnik, A. (2010). Sulforaphane-a possible agent in prevention and therapy of cancer. Postepy Hig Med Dosw (Online) 64, 590-603.

Van Cutsem, E., Moiseyenko, V. M., Tjulandin, S., Majlis, A., Constenla, M., Boni, C., et al. (2006). Phase III study of docetaxel and cisplatin plus fluorouracil compared with cisplatin and fluorouracil as first-line therapy for advanced gastric cancer: a report of the V325 Study Group. J. Clin. Oncol. 24, 4991-4997. doi:10.1200/JCO.2006.06.8429

Wang, X., Govind, S., Sajankila, S. P., Mi, L., Roy, R., and Chung, F. L. (2011). Phenethyl isothiocyanate sensitizes human cervical cancer cells to apoptosis induced by cisplatin. Mol. Nutr. Food Res. 55, 1572-1581. doi:10.1002/mnfr.201000560

Wu, X., Zhou, Q. H., and Xu, K. (2009). Are isothiocyanates potential anti-cancer drugs?. Acta Pharmacol. Sin 30, 501-512. doi:10.1038/aps.2009.50

Xiang, Z., Huang, X., Wang, J., Zhang, J., Ji, J., Yan, R., et al. (2018). Cross-database analysis reveals sensitive biomarkers for combined therapy for ERBB2+ gastric cancer. Front. Pharmacol. 9, 861. doi:10.3389/fphar.2018.00861

Xiao, D., and Singh, S. V. (2010). Phenethyl isothiocyanate sensitizes androgenindependent human prostate cancer cells to docetaxel-induced apoptosis in vitro and in vivo. Pharm. Res. 27, 722-731. doi:10.1007/s11095-010-0079-9

Yang, M. D., Lai, K. C., Lai, T. Y., Hsu, S. C., Kuo, C. L., Yu, C. S., et al. (2010). Phenethyl isothiocyanate inhibits migration and invasion of human gastric cancer AGS cells through suppressing MAPK and NF-kappaB signal pathways. Anticancer Res. 30, 2135-2143.

Yu, W., Chen, Y., Dubrulle, J., Stossi, F., Putluri, V., Sreekumar, A., et al. (2018). Cisplatin generates oxidative stress which is accompanied by rapid shifts in central carbon metabolism. Sci. Rep. 8, 4306. doi:10.1038/s41598-018-22640-y

Zhang, Y. (2010). Allyl isothiocyanate as a cancer chemopreventive phytochemical. Mol. Nutr. Food Res. 54, 127-135. doi:10.1002/mnfr.200900323

Zhao, C. M., Hayakawa, Y., Kodama, Y., Muthupalani, S., Westphalen, C. B., Andersen, G. T., et al. (2014). Denervation suppresses gastric tumorigenesis. Sci. Transl. Med. 6, 250ra115. doi:10.1126/scitranslmed.3009569

Conflict of Interest: The authors declare that the research was conducted in the absence of any commercial or financial relationships that could be construed as a potential conflict of interest.

Copyright (c) 2021 Rabben, Kodama, Nakamura, Bones, Wang, Chen, Zhao and $\emptyset$ verby. This is an open-access article distributed under the terms of the Creative Commons Attribution License (CC BY). The use, distribution or reproduction in other forums is permitted, provided the original author(s) and the copyright owner(s) are credited and that the original publication in this journal is cited, in accordance with accepted academic practice. No use, distribution or reproduction is permitted which does not comply with these terms. 